\title{
Aging, its Current Challenges to Life Scientists Yong $\mathrm{Li}^{*}$
}

Department of Pediatric Surgery, and Department of NanoMedicine and Biomedical Engineering, University of Texas, School of Medicine, Center for Stem Cell Research and Regenerative Medicine, University of Texas Health Science Center at Houston (UT Health), 1825 Pressler St. Houston, TX 77030, USA

\section{Introduction}

Lifespan has a time limitation in all active individuals; populations are aging worldwide. However, a life development that advances from young to old, and finally death, is affected by complicated information, the processes are indeed constantly fluctuating as recently discovered in life sciences. Thus, the wishes of projects in prolonging life or extending lifespan have been of great historical interest, and are now becoming possible through current breakthrough in bioscience and medicine. As a fact, our average lifespan has been rising dramatically since the last few decades, which has lead to both more and more demands and knowledge in aging coming to us. This means that people are living longer, and the number of older persons is increasing; we will face more challenges than at any other time in history from the approaching aged populations and curing aging diseases. Further improvements to longevity and quality of life among the elderly is theoretically possible based on orthologous comparisons with long-lived species; however, technical approaches are truly challenging since there are still millions of mysteries in our bodies that we don't know yet.

The new Journal of Aging Science, a specific journal that targets aging studies, will not only bring to you updates of science and knowledge in aging research and clinical medical applications, but also bring to you not just wishes but hopes in your reading.

\section{Current Aging Studies}

Age and aging processes have been considered complex even with multiple factors. The conventional aging research mostly depends on examination of individual genes, proteins, and other intrinsic or extrinsic factors in isolation. However, the processes of aging involve the interaction of physical, biological, psychological, social and cultural aspects that are complex; application of knowledge about all aspects of aging in a wide range of settings are required. Thus aging studies are systemic and entail several fields of knowledge and technologies. In the post-genomic era, aging research is increasingly conducted at the systems-level: DNAs, genes, telomere lengths, stem cells, and environments [1,2]. Aging increases the rate of human diseases [3-6], such as Alzheimer's disease, Parkinson's disease, stroke, cardiovascular disease, diabetic disease, tumors, sarcopenia, epilepsy and depression, which has led to more and more apprehension among the elderly. Antiaging may decrease the rate of these diseases.

Aging also is affected by personal habits, diet and living environments beside medical issues. The effects of physical exercise, drugs, vitamins, hormones and antioxidants may have an impact on longevity $[7,8]$. There so many other reasons for physiological decline with rising age. A philosophical debate on whether indefinite life extension is desirable due to such issues as overpopulation or various cultural and religious impacts need to be addressed $[9,10]$.

\section{Future Challenges in Aging Medicine}

Aging appears to be a complex biological process whereby the functional capacity of the body diminishes with time, ultimately leading to death of the individual. Understanding what is currently known about aging is vital for responding intelligently to an aging workforce [11]. Planning, marketing and delivery of services to people who are aging, and educating individuals upon whom aging will have an impact are also important. Hopes arise from other life forms, such as turtles and some fishes that can survive hundreds of years, and some amphibians, which can re-growth their missing tissues or organs without aging limitation. Studies of these animal models could give some clues to age prevention; however, the main advance in aging studies may come from current laboratory experiments to know how some human key genes mutate or become activated during aging [1214]. Clues from these studies may move to the next step of prevention of human cell aging in a petri dish, then move to tissues and organs, and finally to each individual. More confidence in solving some of the issues arising from aging comes from the constant influx of new technologies. Some techniques make approaches of aging study easier, faster and more distinct; some new drugs may make a revolution in age prevention. Thus prevention or replacement of aged organs, and extension of lifespan, and rapid treatment of age related human diseases are possible in the near future.

\section{References}

1. Garinis GA, van der Horst GT, Vijg J, Hoeijmakers JH (2008) DNA damage and ageing: new-age ideas for an age-old problem. Nat Cell Biol 10: 1241-1247.

2. Blackburn EH, Greider CW, Szostak JW (2006) Telomeres and telomerase: the path from maize, Tetrahymena and yeast to human cancer and aging. Nat Med 12: 1133-1138.

3. Bonetta L (2002) New study on aging heart. Nat Med 8: 201.

4. Ahima RS (2009) Connecting obesity, aging and diabetes. Nat Med 15: 996997.

5. Longo VD, Kennedy BK (2006) Sirtuins in aging and age-related disease. Cel 126: $257-268$.

6. Rossi DJ, Jamieson CH, Weissman IL (2008) Stems cells and the pathways to aging and cancer. Cell 132: 681-696.

7. Denu JM (2007) Vitamins and aging: pathways to NAD+ synthesis. Cell 129 453-454.

8. Collado M, Blasco MA, Serrano M (2007) Cellular senescence in cancer and aging. Cell 130: 223-233.

9. Rullas LR, Zuccarelli AJ, Nutter RL (1967) Aging effect on phage particles leading to an increase in burst size. Nature 216: 1308.

10. Suh Y, Lee KA, Kim WH, Han BG, Vijg J, et al. (2002) Aging alters the apoptotic response to genotoxic stress. Nat Med 8: 3-4.

*Corresponding author: Yong $\mathrm{Li}$, Department of Pediatric Surgery, and Department of NanoMedicine and Biomedical Engineering, University of Texas, School of Medicine; Center for Stem Cell Research and Regenerative Medicine, University of Texas Health Science Center at Houston (UT Health), 1825 Pressle St. Houston, TX 77030, USA, Tel : +713-500-2438; Fax: +713-500-2424; E-mail: yong.li.l@uth.tmc.edu

Received March 13, 2013; Accepted April 28, 2013; Published May 03, 2013

Citation: Li Y (2013) Aging, its Current Challenges to Life Scientists. Aging Sci 1: 104. doi:10.4172/2329-8847.1000104

Copyright: ( $) 2013 \mathrm{Li} \mathrm{Y}$. This is an open-access article distributed under the terms of the Creative Commons Attribution License, which permits unrestricted use, distribution, and reproduction in any medium, provided the original author and source are credited. 
11. Kirkwood TB (2005) Understanding the odd science of aging. Cell 120: 437447.

12. Hadley EC, Lakatta EG, Morrison-Bogorad M, Warner HR, Hodes RJ (2005) The future of aging therapies. Cell 120: 557-567.
13. Hammond SM, Sharpless NE (2008) HMGA2, microRNAs, and stem cell aging. Cell 135: 1013-1016

14. Rando TA, Chang HY (2012) Aging, rejuvenation, and epigenetic reprogramming: resetting the aging clock. Cell 148: 46-57. 